\title{
Occurrence of Grey Mould on Bucida buceras, a Tree of Subtropical Origin, under Indoor Conditions - A Disease Note
}

\author{
Á. RICHWEISZ ${ }^{1}$, M. Z. NÉMETH ${ }^{2}$, L. KISS ${ }^{2}$ and T. ÉRSEK ${ }^{3 *}$ \\ ${ }^{1}$ CITYGREEN Gartengestältung GmbH, \\ Heiligenstädter Lande 11, A-1190 Wien, Austria \\ ${ }^{2}$ Plant Protection Institute, Centre for Agricultural Research, Hungarian Academy of Sciences, POB 102, \\ H-1525 Budapest, Hungary \\ ${ }^{3}$ Faculty of Agricultural and Food Sciences, Institute of Plant Production, University of West Hungary, Vár 2, \\ H-9200 Mosonmagyaróvár, Hungary
}

(Received: 29 January 2015; accepted: 8 February 2015)

In December 2012 then in the following winter season, the occurrence of whitish mycelial coat was observed on the collar of 3- to 6-m high Bucida buceras trees grown in hydrocultures to decorate a spacious indoor community space in Vienna. (This plant [shown in Fig.1] belongs to Combretaceae, Myrtales and com-

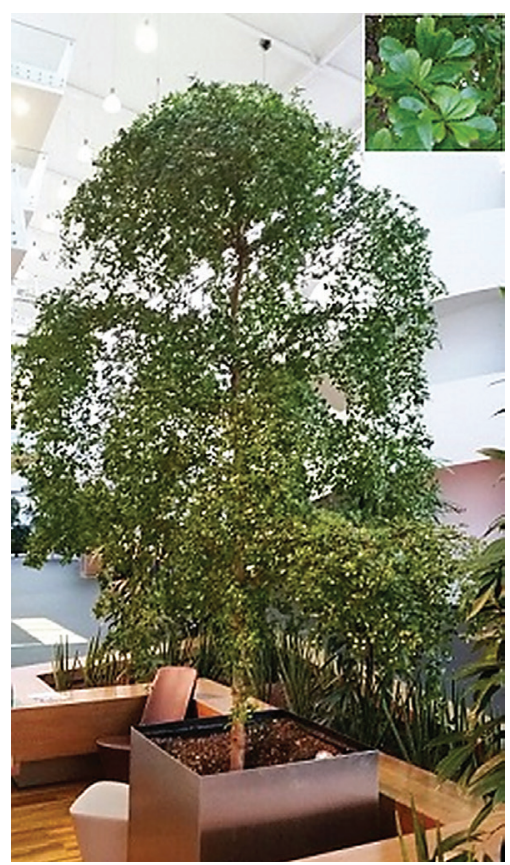

Fig. 1. Bucida buceras tree in hydroculture

\footnotetext{
* Corresponding author; e-mail: ters@mtk.nyme.hu
} 


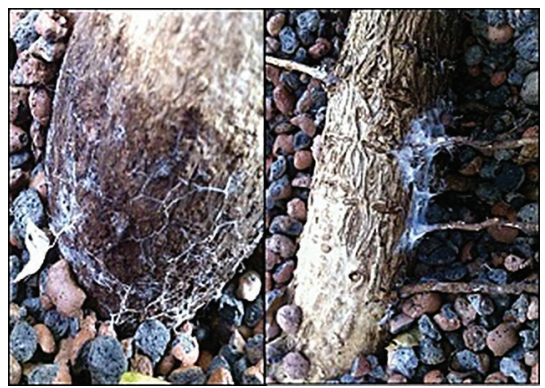

Fig. 2. Mycelium of Botryotinia fuckeliana on the collar (left) and the roots (right) of Bucida buceras

monly named black olive tree, bullet tree, gregorywood and oxhorn bucida.) The mycelium-infested area of the bark appeared to be water-soaked. Near the surface of the potting mix (earth ball embedded in clay pebbles), the roots were also covered with whitish mycelia (Fig. 2). Over the winter season when the indoor temperature increased from $20^{\circ} \mathrm{C}$ to $25^{\circ} \mathrm{C}$, these symptoms were unnoticeable. Regardless of the season, the rhizosphere contained numbers of sclerotia, dark-grey, globose and 8-12 mm in diameter that occasionally developed rhizomorph-like mycelial cords.

Direct plating of mycelium fragments from the bark and sclerotia from the rhizosphere onto potato dextrose agar amended with ampicillin $(500 \mathrm{mg} / \mathrm{l})$ eventually yielded pure fungal cultures of similar characteristics. Cultures routinely incubated in the dark developed white and submerged colonies with sparse aerial mycelia. The fungus grew well between $10^{\circ} \mathrm{C}$ and $25^{\circ} \mathrm{C}$, and failed to grow at either $5{ }^{\circ} \mathrm{C}$ or $32^{\circ} \mathrm{C}$. The optimal growth was measured at $20^{\circ} \mathrm{C}$ with an average radial growth rate of $11 \mathrm{~mm}$ per day. After 10 to 12 days, a ring of sclerotia begun to develop near the edge of the colonies; they turned dark grey and sized 3-8 mm. Rather misleadingly, neither conidia, nor sexual spores were observed in these cultures. However, when the fungus was cultured in natural light under laboratory conditions at $25^{\circ} \mathrm{C}$, a completely different colony pattern was observed; it was cottony, greyish then dark grey, and produced abundant hyaline conidia borne on grey, branching tree-like conidiophores. Conidia were one-celled and egg-shaped, and their dimensions fell in the range of 9.89-14.63 (11.48 \pm 0.31$) \mu \mathrm{m} \times 7.05-10.05(8.31 \pm 0.20) \mu \mathrm{m}$. These features concurred with those characterising the polyphagous grey mould fungus Botryotinia fuckeliana (anamorph: Botrytis cinerea) (Elad et al., 2007). The ITS1/ITS2 including the 5.8S subunit of rDNA of one of the isolates were amplified with primers ITS1-F/ ITS4, then the PCR products were sequenced. The ITS sequence determined in this way was identical to known sequences of B. fuckeliana strains, e.g. that of CBS 131.28 (GenBank accession number: KF859918), the type material of Botrytis cinerea f. lini, DAOM 231372 (GenBank accession number: KF859924) and so on.

Pathogenicity tests resulted in rapidly (within 2 weeks) developing disease symptoms around the site of wound inoculation with a 5-mm-diametre mycelial agar plug: fruit rot on apple and lemon in the laboratory, and sunken lesions on stems of hydrocultured ornamental plants such as the herbaceous Monstera deliciosa and the woody Dracena marginata. To fulfill Koch's postulates, the fungus was re-isolated from symptomatic apple fruit, and was found to exhibit the afore-mentioned morpho-physiological characteristics.

Inoculation test on Bucida was not performed because of the costly risk i.e., the sale price of the trees is $€ 3$ to 10 thousand. Consequently, the actual sensitivity of Bucida to grey mould remains uncertain, so much the more because this plant species has not been recorded as a host of the pathogen or other important parasitic fungi in natural (subtropical) environment (e.g. Whelburg et al., 1975). To our knowledge, this report is the first description of Botryotinia fuckeliana on Bucida buceras. In addition to the fact that periodic emergence of fungal mycelia on the trunk impairs the tree's aesthetic appearance, the sclerotia resting in the potting mix may cause more serious problems in the long term. However, it cannot be precluded that the elevated indoor temperature reduces disease progression and thus the economic importance of the pathogen on this plant.

Keywords: Bucida buceras, Botryotinia fuckeliana, grey mould. 


\section{Literature}

Elad, Y., Williamson, B., Tudzynski, P. and Delen, N. (eds) (2007): Botrytis: Biology, Pathology and Control. Dordrecht, The Netherlands, pp. 1-367.

Whelburg, C., Alfieri, S. A., Langdon, K. R. and Kimbrough, J. W. (1975): Index of Plant Diseases in Florida. Florida Department of Agriculture and Consumer Services, Gainsville, FL, p. 73. 